\title{
PREVALENCE AND FACTORS ASSOCIATED WITH METABOLIC SYNDROME AMONG FEMALE BATIK WORKERS
}

\author{
Yayuk Hartriyanti, Hana Mutia Afifah, Perdana Samekto \\ Department of Health Nutrition, Faculty of Medicine/Public Health/Nursing, \\ Universitas Gajah Mada
}

\begin{abstract}
Background: Metabolic syndrome is a cluster of conditions, including (1) increased blood pressure, (2) high blood sugar, (3) excess body fat around the waist, and (4) abnormal cholesterol or triglyceride levels that occur together, increasing the risk of heart disease, stroke and diabetes. Metabolic syndrome is closely linked to overweight or obesity and inactivity such as working as a batik worker. This study aimed to estimate prevalence and to determine factors associated with metabolic syndrome among female batik workers.

Subjects and Method: This was a cross-sectional study conducted in Kampung Batik Giriloyo, Imogiri, Bantul, Yogyakarta. A total of 65 female batik workers were selected for this study. The dependent variable was metabolic syndrome. The independent variables were nutrition intake and nutrition status. Metabolic syndrome was measured by blood pressure, blood sugar, triglyceride, high density lipoprotein (HDL) cholesterol, and waist to hip ratio. To be diagnosed with metabolic syndrome, one would have at least three of these risk factors. Nutrition status was measured by body mass index. The other data were collected by questionnaire. The data were analyzed by chi square test with odds ratio as the measure of association.

Results: The prevalence of metabolic syndrome was $18.5 \%$ among female batik workers. The risk of metabolic syndrome increased with high fat intake $(\mathrm{OR}=4.75$; $\mathrm{p}=0.030)$ and overweight or obesity $(\mathrm{OR}=5.23 ; \mathrm{p}=0.002)$.

Conclusion: The prevalence of metabolic syndrome is $18.5 \%$ among female batik workers. The risk of metabolic syndrome increases with high fat intake and overweight or obesity.
\end{abstract}

Keywords: metabolic syndrome, prevalence, risk factor, batik worker.

\section{Correspondence:}

Yayuk Hartriyanti. Department of Health Nutrition, Faculty of Medicine/Public Health/Nursing, Universitas Gajah Mada, Yogyakarta, Indonesia.

Email: uke.mahendradhata@gmail.com. Mobile: 08129030997 